\title{
15 Untitled First Draft Dictated on the Maladjusted Child
}

The well-integrated individual feels able to orient himself in the chaos of life when he finds a certain security through effort and socially useful activity. The maladjusted individual develops inferiority, [more and more intense, EP] feelings the more he feels himself incapable of making a useful contribution to society.

These children never contributed anything useful to their community; their contribution was destructive, useful only to their enemies, harmful to their own society. No wonder they feel not only inferior but even guilty and ashamed that they could not stand up courageously against the pressure which forced them to this sort of social activity.

(2)

Inferiority feelings, Alfred Adler teaches, can be the motivating power behind the striving for achievement. There is a lot of inferiority feeling in these children; there is enough motivating power for striving for achievement. But to harness this power to constructive goals we must develop this inferiority feeling into a social feeling. The ideal of perfection for mankind, for the nation, for a party, for the gang, are such constructive goals.

These children have suffered so much through injustice that only justice in its purest form can satisfy them. They have suffered so much cruelty that only the fullest kind of humanity and brotherhood will satisfy them. They have seen so much ugliness in the fighting of every one to save his own hide that nothing but the truest and completest community spirit will satisfy them, and if they don't get it, they will seek revenge and will themselves become unjust, cruel and self-seeking toward those dependent on them.

(3)

While the well-adjusted individual finds satisfaction in the rewards of socially useful work, rewards for these children's efforts came only when they had done something socially destructive. In addition to the work to which they were forced by the enemy, they did antisocial work on their own, hoping the better to survive thereby. They became informers against others in their group; they stole from their friends. Some of them, stronger in character, developed a kind of social organism by building gangs out of the material of the concentration camps. Their socially useful activity was useful only for their own small gang, not for a larger community. Nevertheless they got all the satisfaction out of it

Ә Open Access. (c) 2021 Frank Jacob, published by De Gruyter. (c) BY-NC-ND This work is licensed under the Creative Commons Attribution-NonCommercial-NoDerivatives 4.0 International License.

https://doi.org/10.1515/9783110679410-015 
and now that the pressure has been removed, they continue to work for their gang in the same way. But now the larger community around them is no longer a hostile community, it is the society to which they must adjust if they are to avoid becoming

outcasts, neurotic solitaries, or dangerous outlaws.

But the gang spirit is something for us to start with. It has all the emotional and social elements of adjustment to a social organism; it must simply be developed from gang to community spirit. That's all, but it's a lot. The gang was for these children something understandable, something necessary to their survival, something that protected them. They will accept a new and larger community only if it provides them with at least a feeling of belonging and security they found in the gang. We must give them more; we must give them something of which they can be proud, not only something that gives them a relative security. Our experience teaches that they are highly critical. They analyse our social setup carefully and are not satisfied with it. Theirs is a high ideal of perfection and we are certainly far from perfect. Theirs is the longing for a society diametrically different from that in which they lived before. We have to teach them to integrate to an actual society. If we could only give

(explain why their demands on society are so exacting, why so sensitive to all its imperfections)

them one that approaches their ideal! Failing this, they may withdraw in revenge or their inferiority feelings may be hypercompensated as wishful daydreams and the weaker and smaller they are, the greater will be the position they achieve in such dreams. They will develop an exaggerated superiority feeling to overcome their deep inferiority complex, a superiority feeling expressed in aggressiveness toward those who are weaker or whom they hate because they hinder them in their struggle for supremacy. All these drives can be developed on an individual basis or on the basis of a gang or a larger community. We should not be surprised to find these children among the terrorists of Palestine.

Another way out of their plight is to take refuge in disease, unhappiness, the pity of others, neuroses (and psychoses).

Our education must work in the direction of teaching these youngsters how to overcome their inferiority feeling, how to fit into a community life successfully. 
With great eagerness they will grab the opportunity to study or learn a trade enabling them to support themselves and no longer be dependent, and more than this, giving them a chance to contribute to the wellbeing and development for others.

They must find their place in the social setup. The pathological way out can be to subordinate the child's drives. He will be as a superior who can use the abilities and eagerness of these young people for something that looks ideal to them. The normal way is to let the child have a place of his own in the democratic society, the possibility to discuss, to participate in decisions, and to help carry them out.

\section{(7)}

Every individual is a psychobiological entity. Changes in the one sphere will always bring about alterations in the other. Former hunger have(?) its influence on the psyche and emotions of these children, just as overeating now has its influence. It is not only the physiological change from poor to better nourishment; both being afraid of not getting enough, and being sure of getting enough must influence their development greatly. To give the children security must be one of our first steps. It's nice for a tearjerker to show a child released from concentration camp taking a piece of bread from the table and putting it secretly into his pockets. Emotionally it is a very unhealty situation, which may jeopardize all of our psychological efforts and minimize the educational influence we hope to exert if the child cannot get rid of the feeling of insecurity manifested in such an act of fear.

Overeating is another expression of this feeling of insecurity. It might have been all right for first days after liberation to let the children eat at much as is physiologically possible with out harm, but it would be emotionally wrong to permit this to continue. We must make the children aware that the physiological hunger feeling can be satisfied with less food. We must give them the conviction that it is unnecessary for them to stuff everything in that they can get their hands on, they must know that there will always be enough from now on.

We cannot assure them, and we should not assure them, that there will always be enough because they will get it as a gift from society. They must be educated to our world, in which food is not guaranteed to everyone, not even to every child, even under normal conditions. They must know that we must all work for our living. We must instruct them and convince them that they will have an opportunity to prepare 
For earning a living and that until they are ready for that (?) they will receive what they need because of their special situation. We must show them possibility and awaken in them the desire to work for their living, to give society in return for what they receive from society. Only thus can we avoid developing "professional Schnorrers" (professional beggars).

Alfred Adler has taught us that "insufficiency of effectiveness" can be due to the morbid phenomena of the civilisatory conditioning process. Where could this be truer than with these children? Their insufficiency of effectiveness has been to a great extent, provoked by the deadly phenomena of Nazism; their personalities were formed in a childhood whose strongest physical and psychic impressions forced on them a consciousness of their insufficiency; they wee doomed to slavery; under purely negative pressure from their slavedrivers, they were forced to develop an effectiveness of no significance for their own development but merely adequate to keep them alive. Thus the children

ordered to drag dead bodies from the gas chamber to the crematorium derived no kind of personal satisfaction from their work but were simply aware that if they did this work inefficiently they would be killed or brutally beaten.

Without any of the satisfaction of work well done, without childish or adolescent playwithout identification and the winning of prestige through the success of parents, relatives or nation, without belonging to anything but a gang forced to unity by common fear and common distress and yet with everyone for himself for the sake of survival - their emotional development was to a very great extent influenced only by negative factors, with no positive outlook (constructive) for the present or for the future. Certainly, there was some hope that one day the Nazis would be beaten; certainly there was some hope that one day they would be liberated.

And then liberation came. There was enough food now for the first time. A few of them could also go home. They were willing to be led to a constructive future. But nothing was offered them. We missed a tremendous opportunity, and this opportunity will never be ours again. It will be harder now, even under the most favorable circumstances, to put these children on the right road. They were able to keep the emotional effects of being victimized by their enemies the Nazis; but now they were disappointed by their liberators. They were cheated in their expectations and they were cheated even when our intentions were best. 
There are the Jewish children. Some of them wanted to live now in a free and democratic world. Some even expected to find it in another democratic Germany, such as they had known before Hitler. Others saw their only hope in a Jewish homeland in Palestine. Nothing of this was granted them. Worst of all, no constructive direction

was afforded to individual development or the necessary reintegration into a community of some kind. There were cases where the children were offered a highly unrestricted life. A children's camp, for instance, under their own administration, run by self-government, where everyone could do as he liked, where the children could stay away from the camp overnight, could take what they wanted, eat what they wanted, and where those in charge thought this the right new life after their slavery.

We do not believe that even very mature adults would enjoy such a life. These children did not only not enjoy it; they were cheated of their right to get into a stable society again, to be educated to a life where they would not run wild but would belong, where they would not only have rights but also duties and it is a right to have duties toward a family or a community, and Adolescents especially long for this right to duties.

The children were longing for a superior environment into which their personalities, now raised to a level higher than it had been in the past, could fit. The emotionally beneficial advantage of this situation has been lost, but it is never too late. We still have a chance to use this desire, slumbering in these children and still very strong in them, for a better development - if we can offer them this superior environment longed for and expected in their dreams, waking and sleeping, while they slaved in Hitler's camps.

When we get up in the morning after a good night's sleep, our bodies are not the same as the bodies we laid down the night before. When we have worked very hard or given ourselves a workout in a stiff game of tennis, our bodies are changed. Our minds and personalities are not inflexible or unchangeable either; they are as alterable as our bodies. How we change depends partly on outside impressions. Resting or working, eating too much or too little, all these influence our bodies. Environmental impressions, pleasure or pain, fear or security, happiness or unhappiness, excitement or tranquillity all change our minds and personalities. 
The children who went through war and persecution went through abnormal bodily development by frequent hunger and frequent overwork, by highly specialized work employing only a limited number of muscles, by lack of sleep. They got no satisfaction out of the work they did for the enemy. For the children in concentration and slave labour camps there was no father, no mother to be proud of their efficiency and their accomplishments. There was no encouragement spurring them to eagerness, only fear and anxiety.

No doubt months and years of slave labour, months and years of abnormal emotional development, separation from their families, separation from a community appropriate for the child, have greatly influenced the bodies and minds, the emotions and the personalities of the children. The knowledge of this destructive and negative influence, however, should not let us overlook the fact that it also implies the possibility and hope for a change to the better. There are only a few cases where the threshold of flexibility was overstepped. That we must know is in which direction the overemphasis of the former years was laid. Then we can find the compensation.

Alfred Adler has taught us that the disfunction in one or another organ system will be compensated in the cyclical sphere. Hypercompensation takes place where weakness and smallness are to be overcome.

There is one factor situation where these facts are most clearly visible. Hunger and fear of not being fed sufficiently have influenced the growth of the body and provoked anxiety about hutnger and insufficient nourishment to the point of determining the personality and emotional development of children. It will be one of the most important tasks to handle this distortion from the first day we get these children out of their abnormal environment.

England - Buchenwald children 